\title{
Ultraviolet Reflector Materials for Solar Detoxification of Hazardous Waste
}

Gary Jorgensen

Rangaprasad Govindarajan

Solar Energy Research Institute 1617 Cole Boulevard

Golden, Colorado 80401-3393

A Division of Midwest Research Institute Operated for the U.S. Department of Energy under Contract No. DE-AC02-83CH10093

July 1991 


\title{
NOTICE
}

This report was prepared as an account of work sponsored by an agency ot ihe United States jovernment. Neither the United States government nor any agency thereot. nor any of their employees. makes any warranty, express or imptieo. or assumes any legal liability or responsibility for the accuracy, completeness, or usefulness of any information, apparatus, product, or process discloseri, or represents that its use would not intringe privately owned rights. Reference herein to any specific commercial product, process, or service by trade name. trademark, manu!acturer, or otherwise does not necessarily constitute or imply its endorsement, recommendation, or favoring by the United States governmient or any agency thereot. The views and opinions of authors expressed herein do not necessarily state or reflect those of the United States nol ernment or any agency thereot.

\author{
Printed in the United States uf America \\ Avallable trom: \\ National Technical Information Service \\ U.S. Department of Commerce \\ 5285 Port Royal Road \\ Springtield. VA 22161
}

Price: Microfiche A01

Frinted Copy $\mathrm{AO}$

Codes are used for pricing all publications. The code is determiled by the n!mber of pages in the publication. Information pertaining to the pricing codes can be found in the current issue of the following publications which are gerterrally available in most libraries: Energy Research Abstracts (ERA): Government Repor's Announcements and Index (GRA and 1): Scientific and Technic.al Abstract Reports (STAR); and publication NTIS.PR-360 available trom NTIS at the above address. 


\author{
Ultraviolet reflector materials \\ for solar detoxification of hazardous waste
}

Gary Jorgensen and Rangaprasad Govindarajan

Solar Energy Research Institute

1617 Cole Boulevard, Golden, Colorado 80401

\begin{abstract}
Organic waste detoxification requires cleavage of carbon bonds. Such reactions can be photo-driven by light that is energetic enough to dissupt such bonds. Alternately, light can be used to activate catalyst materials, which in tum can break organic bonds. In either case, photons with wavelengths less than $400 \mathrm{~nm}$ are required. Because the terrestrial solar resource below $400 \mathrm{~nm}$ is so small (roughly $3 \%$ of the available spectrum), highly efficient optical concentrators are needed that can withstand outdoor service conditions. In the past, optical elements for solar application have been designed to prevent ultraviolet (UV) radiation from reaching the reflective layer to avoid the potentially harmful effects of such light on the collector materials themselves. This effectively forfeits the UV part of the spe:trum in return for some measure of protection against optical degradation. To optimize the cost/performance benefit of photochemical reaction systems, optical materials must be developed that are not only highly efficient but also inherently stable against the radiation they are designed to concentrate.
\end{abstract}

The requirements of UV optical elements in terms of appropriate spectral bands and level of reflectance are established based upon the needs of photochemical applications. Relevant literature on UV reflector materials is reviewed which, along with discussions with industrial contacis, allows the establishment of a data base of currently available materials. Aithough a number of related technologies exist that require UV reflectors, to date little attention has been paid to achieving outdoor durability required for solar applications.

\title{
1. INTRODUCTION
}

Presently, two solar technologies are being developed that provide a creative approach to environmental waste detoxification. ${ }^{1}$ The first technology remediates dangerous chemicals in aqueous form and the second deals with treatment of chemicals in the gas phase. Both processes rely on the availability of near-ultraviolet (roughly the UV-A region) photons in the spectral range of $300-400 \mathrm{~nm}$. The terrestrial resource within this bandwidth is extremely limited. ${ }^{2}$ Approximately $3 \%$ of the integrated irradiance of an air mass 1.5 direct normal solar spectrum is contained below $400 \mathrm{~nm}$.

Several selection criteria can be established for candidate UV reflector material consideration. Materials are desired that provide maximum specular reflectance of the solar resource at the wavelengths of interest $(300-400 \mathrm{~nm})$, which are optically durable (that is, they retain high performance for reasonable service lifetimes under outdoor environmental exposure), and which are low in cost. For some applications (such as low temperature processes), spectral splitting (in which the visible and nearinfrared part of the spectrum are not reflected) may be desirable.

Detoxification of organic waste requires severing of carbon bonds. One approach is disassociation by direct absorption of UV photons. Unfortunately, this process exhibits very low efficiencies for an already low-level resource. An alternate approach is to use $\mathrm{UV}$ activation of a catalysi material (such as $\mathrm{TiO}_{2}$ ), which is capable of breaking organic bonds with a higher efficiency. Sensitization of such catalysts to slightly higher wavelengths would substantially enhance the throughput of the reaction. For example, if wavelengths out to $420 \mathrm{~nm}$ were usable, a $50 \%$ increase in reaction efficiency could be obtained.

\section{REQUIREMENTS}

Mirror materials are needed that have a specular reflectance between $300-400 \mathrm{~nm}$ capable of achieving the concentration levels associated with the various detoxification applications. Because solar concentrators usually are curved surfaces, an insensitivity of reflectance to angle of incidence efferts is desirable. Outdoor durability must be maintained for extended service 
lifetimes. Production scale-up to large areas must be possible. If multilayer coatings are used, the number of layers should be restricted to as few as possible to minimize cost. Overall cost should be low enough to allow solar detoxification to be competitive with alternate technologies.

\subsection{Optical performance requirements}

The opticai quality requirements of UV materials are related to the levels of concentration needed by the particular applications being considered. For example, for aqueous detoxification, concentration ratios of $1 \mathrm{X}-20 \mathrm{X}$ are envisioned.' Such levels can be obtained by line focus (parabolic trough) concentrating systems. For such a configuration, the concentration ratio (C) is related to optical performance parameters $\mathrm{as}^{3}$

$$
C=\frac{D}{f\left(2 \sigma_{\text {2lopo }}+\sigma_{\text {mon }}\right)}
$$

where

$$
\begin{aligned}
& \text { D = width of the aperture of the trough } \\
& \text { f } \quad=\text { focal length } \\
& \sigma_{\text {slcpo }}=\text { slope error } \\
& \sigma_{\text {nim }} \quad=\text { half angular extent of (Gaussian) sun } \\
& =2.73 \mathrm{mrad}
\end{aligned}
$$

Including reflectance losses and tracking and specularity errors Equation (1) becomes:

$$
C=\rho_{v} C_{0} \frac{\sigma_{\mathrm{mm}}}{\sigma}
$$

where

$$
\begin{aligned}
& \rho_{1} \quad=\text { specular reflectance } \\
& C_{c} \quad=\text { concentration in the absence of surface and tracking errors } \\
& \sigma \quad=\text { total optical crror }
\end{aligned}
$$

For a parabolic trough, $C_{0}$ is roughly $y^{4} 250 . \rho_{s}$ and $\sigma$ are defined $a s^{5}$

$$
\rho_{1}=\rho_{2 \pi}\left[1-e^{-\left(\alpha / \sigma_{0}\right)^{2} R}\right]
$$

and

$$
\sigma=\sqrt{\left(2 \sigma_{\text {alopo }}\right)^{2}+\sigma_{8}^{2}+\sigma_{\text {track }}^{2}+\sigma_{\text {run }}^{2}}
$$

with

$$
\begin{array}{ll}
\rho_{2 \pi} & =\text { hemispherical reflectance } \\
\alpha & =\text { acceptance half angle of the absorber tube } \\
\sigma_{1} & =\text { specularity error } \\
\sigma_{\text {track }} & =\text { tracking error }
\end{array}
$$

The acceptance half angle, $\alpha$, can be related to the level of concentration of the trough as ${ }^{6}$

$$
\alpha=\sin ^{-1}\left[\frac{\sin \phi}{\pi \mathrm{C}}\right]
$$

with

$\phi \quad=$ rim angle of the trough 
The rim angle can be calculated from the $\mathrm{f} / \mathrm{D}$ ratio as

$$
\phi=2 \tan ^{-1}\left[\frac{1}{4(f / D)}\right]
$$

Thus, for a given geometric configuration (f/D), a rim angle is defined that can be used in eqn. 5 to obtain the acceptance half angle as a function of concentration. Using this result in eqn. 3 and substituting eqns. 3 and 4 into eqn. 2 gives an expression for the level of concentration as a function of hemispherical reflectance and the optical errors. For a given level of concentration, these equations can be solved to generate families of curves representing error budget and optical performance criteria for designed levels of concentration. As an example, Figure 1 presents curves at concentration levels of $5 \mathrm{X}$ and $20 \mathrm{X}$ for hemispherical reflectances of $.35, .55, .75$, and .95 . Hemispherical reflectance and specularity $\left(\sigma_{z}\right)$ are optical performance parameters inherent to the reflector material. The optical errors represented along the ordinate axis are design targets that can be traded off for $\sigma_{1}$ and/or $\rho_{2 \pi}$. If $\rho_{2 \pi}=.75,20 \mathrm{X}$ concentration can be achieved with an $\mathrm{f} / \mathrm{D}=.35$ system with a specularity of 14 $\mathrm{mrad}$ and no slope or tracking errors. Similarly, if the reflector is perfectly specular $\left(\sigma_{1}=0, \rho_{2}=\rho_{2 \pi}\right)$, an error budget of $25 \mathrm{mrad}$ can be afforded for slope and tracking errors. Typical errors for state-of-the-art solar concentrators are $\sigma_{3} \approx 1.5 \mathrm{mrad}, \sigma_{\text {dlope }} \approx 3 \mathrm{mrad}$, and $\sigma_{\text {track }}=2 \mathrm{mrad}$. This means that the desired levels of concentration can readily be obtained with minimal effort. Of equal importance is the fact that lower hemispherical reflectance values might be acceptable by adhering to an error budget only slightly more stringent.

A similar analysis can be carried out for a two-axis concentrating system, for example, a parabolic dish collector. Such a collector may be required to achieve conicentrations of $300 \mathrm{X}-1000 \mathrm{X}$ for gas phase detoxification. ${ }^{1}$ Figure 2 presents the allowable optical errors consistent with achieving these levels of concentration. As can be seen, the error budget for the higher concentrating two-axis system is somewhat more restrictive than for the trough design.

For multilayer coatings, reflectance can be a strong function of the angle of incidence $\left(\theta_{0}\right)$ due to the variation in optical path length (OPL) through each layer. An area-weighted average angle of incidence over a concentrator surface $(\theta)$ should be used for design purposes. As the angle of incidence varies about the nominal design, the phase difference between the waves reflecting from all of the interfaces will increase for $\theta_{0}<\theta$ (resulting in a shift of performance toward longer wavelengths), and the phase difference will decrease for $\theta_{0}>\theta$ (resulting in a shift of performance to shorter wavelengths). To minimize such shifts in performance with angle, materials having the highest index of refraction possible should be used. ${ }^{7}$ The reason for this is that the effective index (due to changes in optical path length with angle of incidence) of high index materials varies less than that of lower index materials. Unfortunately, this places limitations on the availability of optical materials in the UV part of the spectrum.

\section{$\underline{2.2 \text { Cost requirements }}$}

The present cost of linear focus solar collector arrays is roughly $\$ 2.00 / \mathrm{m}^{2}$, which represents $90 \%$ of system equipment costs. ${ }^{8}$ By relaxing optical performance requirements (for example, by operating at lower concentration levels), it is hoped that a reduction in cost by a factor of $2-4$ can be achieved. The reflector element can represent an appreciable fraction of the collector cost. Large volume purchase costs for state-of-the-art mirror materials range between $\$ 20 / \mathrm{m}^{2}$ (for silver polymer refleciors) and $\$ 30 / \mathrm{m}^{2}$ (for glass). Beyond the cost, such reflectors are not appropriate for UV applications. Typically, non-UV transmissive glass is used and UV absorbers are added to polymer films to prevent light-induced corrosion at the silver/polymer interface.

One candidate UV reflector material is an aluminized polymer film (SA85 from 3M Company) having a front surface protective coating without appreciable UV absorption. Although intended for indoor lighting applications and not recommended as an outdoor weatherable film, the price of this commercial product (as low as $\$ 7.50 / \mathrm{m}^{2}$ ) is attractive.

Another candidate is electropolished aluminum having an anodized protective coating $\left(\mathrm{Al}_{2} \mathrm{O}_{3}\right)$. For large volume purchases the price varies between $\$ 8 / \mathrm{m}^{2}$ for "semi-specular" material to $\$ 15 / \mathrm{m}^{2}$ for "highly specular" material. One drawback of these reflectors is their questionable outdoor durability. Typically, thin $(2-3 \mu \mathrm{m})$ oxide layers are nsed to provide some measure of abrasion resistance but little protection against moisture or pollutants is furnished. Thicker oxide layers $(10-50 \mu \mathrm{m})$ are usually specified when anodized aluminum is intended for engineering/marine applications;' the effect of such layers upon specular reflectance needs to be addressed. Another approach is to apply multilayer dielectric (MLD) protective coats over the oxide layer. Considerable added expense can be incurred by the coating process. 
If MLD coatings are considered, improved reflectance (relative to electropolished anodized aluminum) can be achieved by depositing such layers directly onto thin film aluminum. The cost of this process can be substantial. For example, a specially ordered front surface mirror coating on glass intended for outdoor durability and high solar and UV reflectance recently cost $\$ 200 / \mathrm{m}^{2}$ in a "mass produced" mode; another "custom" order was $\$ 800 / \mathrm{m}^{2}$. Although such prices are high, experience in the coating industry indicates that process scale-up and volume production can drastically lower coating costs. An example case study was presented by Seddon ${ }^{10}$ for a front surface reflector comprised of a thin film of aluminum coated by several dielectric layers. Based upon learning curve results, it was shown how drastic reduction in cost could occur with the volume of cumulative production and the progression of coating equipment and technology. Decreases in coating costs from $\$ 175-\$ 200 / \%$ for a $1.8-\mathrm{m}$ batch coater to $\$ 45-\$ 65 / \mathrm{m}^{2}$ for a $3-\mathrm{m}$ carousel coater to roughly $\$ 10 / \mathrm{m}^{2}$ for a continuous coater were indicated.

\section{RELATED TECHNOLOGIES}

Several optical technologies exist that require UV reflecting elements. Although broad similarities exist, the specific requirements of these parallel applications differ considerably from solar needs, particularly in terms of outdoor service durability. Related fields include UV mirrors for medical imaging, astronomical telescopes, microscopy, UV curing, indoor lighting, microlithography, industrial micro machining, and UV laser reflection.

Astronomical applications generally operate at shorter UV wavelengths. ${ }^{11}$ In addition, the operating environment of spaceborne optics is very different than terrestrial conditions. Durability in the presence of atomic oxygen is required; humidity generally is not a concern.

The UV curing process requires high specular reflectance in the spectral region of 200-400 nm. Such reflectors are in relatively close proximity to high intensity UV lamps; the environment in a UV lamp module is relatively aggressive. Exposure conditions include intense UV radiation, ozone and other pollutants (solvents, etc. that outgas from the irradiated coating or treated article), and elevated temperatures up to $150^{\circ}-200^{\circ} \mathrm{C}$. Aluminum is generally the material of choice due to its high reflectance over the wavelengths of interest. In particular, superpure aluminum (99.99\%) provides the best performance; the higher the purity the higher the specular reflectance. Protection against corrosion by the exposure environment must be provided along with the ability to periodically clean the reflector surface. An anodized protective $\mathrm{Al}_{2} \mathrm{O}_{3}$ coating is usually used, even though the anodizing process results in a significant drop in reflectance compared to uncoated aluminum. ${ }^{12}$

Of particular interest is UV curing of optical fiber buffer coatings. For this application, light in the $350-400 \mathrm{~nm}$ region is found to be most important. A special hard coating has been developed, which provides enhanced reflectance (about $8 \%$ higher than standard anodized aluminum) over this spectral range. ${ }^{13}$ The durability of this conting for solar applications is unknown.

A good deal of work has been done in the area of reflector materials for specific UV laser lines. Much of this work has resulted in rather narrow band reflectors tailored to the laser wavelength of interest; broadband UV reflectance has not been adequately addressed. The most frequent concept for achieving high reflectance in the UV has been multilayer dielectric interference coatings. Typically, quarter-wave-thick coatings of high index of refraction materials (such as $\mathrm{Al}_{2} \mathrm{O}_{3}, \mathrm{HfO}_{2}, \mathrm{ZrO}_{2}$, and $\mathrm{Sc}_{2} \mathrm{O}_{3}$ ) are alternated with low index layers (for example, $\mathrm{SiO}_{2}, \mathrm{CaF}_{2}$, and $\mathrm{MgF}_{2}$ ), which are also quarter-wave thick. ${ }^{14} \mathrm{Ten}$ to fifty layer coatings are not unusual. Technical concerns involve controlling the thickness of each layer to within $1 \%-5 \%$, as well as stress development between adjoining layers. In addition, the greater the number of layers the greater the likelihood of significant absorption; scatter at interfaces can al:io be a problem. Although sucin obstacles can be overcome (for small areas and small bandwidth), the resulting process is extremely expensive. In addition, durability is a critical issue. Most durability studies of such coatings have been carried out in terms of laser pulse intensity survivability. Little attention has been paid to outdoor weathering conditions expected to be experienced in solar applications. In particular, low index coatings are known to be sensitive to moisture, which can induce cloudiness ${ }^{15}$ or crazing. ${ }^{16}$

\section{CANDIDATE UV REGLECTOR MATERIALS}

A review of the literature was performed to determine candidate material systems and concepts. Several approaches to front surface UV reflector materials were advocated. A number of alternate innovative ideas were also advanced. Specific recommendations for materials and coating processes were made. 


\subsection{Front surface UV reflectors}

A variety of ways of producing front surface high UV reflecting mirrors are possible; optical durability of candidate constructions must be evaluated. Several bare metal reflectors can be considered. ${ }^{17.19}$ A second approach is to overcoat an appropriate metal with a single dielectric protective layer. ${ }^{20}$ Another strategy is to use MLD coatings to enhance performance as well as protecting the base reflector material. ${ }^{21}$ These approaches rely on tailoring the choice of materials to optimize reflectance in the desired spectral region. The use of more energetic deposition processes can provide greater durability.

The spectral reflectance of a number of candidate front surface metal coatings that have been used in the optical industry is shown in Figure 3. Reflectance values obtained by weighting with a terrestrial air mass 1.5 solar spectrum over wavelengths between $300-400 \mathrm{~nm}$ are also tabulated in Figure 3. These data are for freshly evaporated films. Aluminum is seen to have the highest reflectance across the UV band. The problem with aluminum is that the thin oxide layer, which naturally forms, is not sufficient to protect aluminum in outdoor environments. In such an exposure condition the oxide layer continues to grow and UV reflectance drops off dramatically.

Several ways exist to protect aluminum. One is anodization in which an amorphous aluminum oxide layer is electrolytically grown on the surface of the bulk metal. Such coatings can provide good protection against some chemical attack and good abrasion resistance. Outstanding chemical resistance can be obtained by coating aluminum with tin oxide. ${ }^{22}$ Unfortunately, such a coating results in considerably lower reflectance than anodized aluminum, especially in the UV range. Alternate, more energetic deposition processes can be used, along with different coating materials, to provide front surface aluminum reflectors that are extremely durable in some exposure environments. ${ }^{23}$ Such advanced techniques and materials should be optimized for ultraviolet wavelengths and evaluated in terms of outdoor weather conditions anticipated for UV solar applications.

Silver exhibits very high reflectance above $325 \mathrm{~nm}$ and is frequently used for solar applications. Whereas unprotected silver will tarnish, durable reflector constructions based on silver have been developed. ${ }^{24}$ Surprisingly, the solar weighted reflectance between $300-400 \mathrm{~nm}$ (Figure 3) is quite high, due largely to the fact that within that bandwidth the terrestrial solar spectrum is low where the reflectance of silver is low and is relatively higher where the reflectance of silver is high. For applications that do not require light between $300-325 \mathrm{~nm}$, protected silver would be an attractive candidate.

Although their UV reflectances are lower than that of aluminum, rhodium and platinum ${ }^{25}$ are very corrosion resistant materials. In NASA accelerated weathering tests of these materials as candidate reflectors for space based solar dynamic power systems, rhodium and platinum were found to be extremely resistant to atomic oxygen. ${ }^{26}$ If their hemispherical reflectances can be tolerated (in terms of the error budgets indicated in Figures 1 and 2), thin film front surface mirrors of this type should be considered and tested for terrestrial UV reflector applications.

\subsection{Innovative concepts}

Instead of many layers of different materials, if the properties of one material could be altered during deposition, any generalized index profile could be created offering any designed spectral response. These films are known as gradient-index films.

Gradient-index films are categorized as either digital or analog. The digital designation refers to approximating the continuous index variation by alternating high and low index layers. The analog designation is actually a continuous variation in the refractive index produced through the modification of the composition of the material. Both the analog and digital profiles can be implemented through the use of multiple sources or by modulating the properties of a single material. ${ }^{27}$

The advantages afforded by analog structures are the flexibility of design, modification of material processes, and increased stability in adverse environments. ${ }^{27,28}$ Early methods consisted of multiple sources with individual rate monitors and control was manual and the material mixing theories ${ }^{27}$, which are still controversial, were necessary to determine the index of the composite material. Now codeposition of two or more sources or modification of the process parameters, such as the reactive gas pressure or reactive ion current, are utilized and can be controlled by computers. Several methods are utilized to determine the necessary profile, such as the Fourier transform method. ${ }^{29,30}$

One popular type of gradient-index film is known as a rugate filter. The rugate filter is composed of a periodic refractive index profile based on the superposition of sinusoids to produce any desired index profile. These filters, however, are difficult to produce, very thick $(10-20 \mu \mathrm{m})$, and because of the thicknesses involved can incur stress buildup. ${ }^{31,32}$ 
The determination of the microstructure of the dielectric layers has been prevented by the small thicknesses of the digital layers and therefore, the implications of such microstructures on the performance in terms of durability have also been prevented. Although interfaces have been viewed as a cause of film failure because of impurity segregation and thermal expansion coefficient discontinuity, automation of the deposition process shortens the interruptions between the different source depositions and eliminates the concentration of impurities that are associated with multiple layers or multiple sources. ${ }^{27}$

Aside from the different structures proposed, innovative concepts to increase the reflectance have also been proposed. Several of the following ideas were devised to overcome the absorbing quality of materials as the wavelength decreases in the ultraviolet. One innovative idea was originated by Spiller to increase reflectance using thin aluminum layers separated by nonabsorbing dielectric spacers. ${ }^{33}$ A second method ${ }^{34}$ recognizes that the node, or point of minimum field intensity, should be centered around the absorbing material to minimize the absorption. In the UV where all the indices of refraction approach unity, even if only differences in the absorption coefficient exist, a multilayer coating with reasonable reflectivity is possible.

A method to broaden the reflectance of a multilayer stack is to stagger the layer thicknesses either in a geometric or arithmetic progression. However, to see any improvement over the standard quarter-wave stack requires at least 15 layers. ${ }^{35}$

Although metals and dielectrics have been emphasized, organic films can also serve as protective coatings and interference filters. ${ }^{36}$ Among the advantages are that both sides of the substrate can be coated simultaneously, uniform coatings are possible on curved as well as flat substrates, the process is low-temperature, and short deposition times are required. ${ }^{36}$

\subsection{Materials and coating processes}

All of the concepts for reflectors, bare metals, overcoated metals, all dielectrics, and gradient-index materials rely on the optical constants that are a function of the materials, the deposition process, and the deposition parameters. Material limitations and difficulties in the coating, process result in a limited maximum reflectance. For laser mirror coatings, not many materials have been found to be practical because of the demanding durability requirements, as most potential multilayer materials become absorbing in the UV and VUV. Of the materials available, the properties of thin films deposited by evaporation or sputtering are different from the bulk materials. ${ }^{17,37}$ Consideration of the properties available using current production methods will be discussed, new developments in coating processes to improve deficiencies in the properties will be mentioned, and new materials that can be produced with either the old or new processes will be discussed.

\subsubsection{Deposition processes}

Conventional methods include sputtering and e-beam deposition. Advances in the coating processes include reactive evaporation, activated reactive evaporation, ion assisted evaporation and deposition, ion beam sputtering and gas discharge deposition, reactive ion plating, and laser assisted deposition.

Reactive evaporation ${ }^{32,38,39}$ is used where direct evaporation is not possible because of thermal dissociation or an extremely low vapor pressure for the starting material. Activated reactive evaporation ${ }^{38}$ uses ionized gas to form better stoichiometric films, eliminating absorption from suboxides. Ion assisted deposition ${ }^{38}$ (IAD) involves the bombardment of the growing film by argon and/or oxygen ions. IAD improves the optical properties, adhesion, stability, and environmental durability, and reduces stress in the deposited film. ${ }^{38,40}$ IAD can also be applied prior to deposition to clean the substrate and after deposition to add energy to the film to further improve almost all optical and mechanical properties of that film. ${ }^{38}$ Ion beam sputtering and gas discharge use noble gas ions to bombard the target and momentum transfer ejects atoms or molecules from the target. ${ }^{38}$ The momentum transfer provides the energy to form more dense films, improving the film properties. This type of system is also used for deposition onto large flat substrates. ${ }^{38}$ Reactive ion plating results in very dense films often without columnar microstructure, thereby creating films with excellent properties. ${ }^{38}$ The refractive index is close to the bulk $\mathrm{m}$ in erial, reproducible to an accuracy of $1 \%$, and homogeneous to an optical thickness of almost two avelengths. Laser assisted evaporation uses a lascr to evaporate a source material and is analogous to e-beam evaporation. ${ }^{41}$

\subsubsection{Common materials}

Several recent developments in film deposition processes can form thin films with desired optical characteristics. The combination of process and materials can create a film with the properties to satisfy the requirements for a particular reflector design. Among the material candidates for $\mathrm{UV}$ applications are $\mathrm{ZiO}_{2}, \mathrm{Y}_{2} \mathrm{O}_{3}, \mathrm{ThO}_{2}, \mathrm{Sc}_{2} \mathrm{O}_{3}, \mathrm{PbF}_{2}, \mathrm{MgO}, \mathrm{Al}_{2} \mathrm{O}_{3}, \mathrm{MgF}_{2}, \mathrm{ThF}_{4}, \mathrm{HfO}_{2}$, 
and $\mathrm{CaF}_{2}{ }^{37,39,42,46} \quad \mathrm{Y}_{2} \mathrm{O}_{3}$ and $\mathrm{Sc}_{2} \mathrm{O}_{3}$ suffer from absorption; $\mathrm{ThO}_{2}$ and $\mathrm{ThF}_{4}$ are radioactive; and $\mathrm{PbF}_{2}$, $\mathrm{MgO}$, and $\mathrm{MgF}_{2}$ absorb water. Commonly used high index, low absorption materials are $\mathrm{ZrO}_{2}, \mathrm{HfO}_{2}, \mathrm{Y}_{2} \mathrm{O}_{3}, \mathrm{Sc}_{2} \mathrm{O}_{3}$, and $\mathrm{Al}_{2} \mathrm{O}_{3} ; \mathrm{but} \mathrm{Sc}_{2} \mathrm{O}_{3}$ is expensive and is therefore not as commonly used. $\mathrm{MgF}_{2}, \mathrm{SiO}_{2}, \mathrm{CaF}_{2}$ are the generally accepted low index materials, although they absorb water, changing their indices.

\subsubsection{New material cumbinations and properties}

In parallel to the development of new deposition processes, new material combinations have been developed and investigated. $\mathrm{Y}_{2} \mathrm{O}_{3}-\mathrm{ZrO}_{2},{ }^{37,46} \mathrm{ZrO}_{2}-\mathrm{TiO}_{3},{ }^{47}$ and $\mathrm{HfO}_{2}-\mathrm{Y}_{2} \mathrm{O}_{3}{ }^{46}$ are potential material combinations that have advantageous properties such as homogeneity, low absorption coefficients, and high refractive index values.

Using a mixture of $\mathrm{ZrO}_{2}$ and $\mathrm{ZrTiO}_{4}$ and e-beam deposition, a material in the $\mathrm{ZrO}_{2}-\mathrm{TiO}_{2}$ system was created. The film layers are hard, have good adhesion on glass, are chemically and mechanically durable, and are optically homogeneous. ${ }^{47}$

$\mathrm{ZrO}_{2}$ doped with $\mathrm{Y}_{2} \mathrm{O}_{3}{ }^{37,46}$ is another new material combination candidate. The $\mathrm{Y}_{2} \mathrm{O}_{3}$ is thought to restrain crystalline transformation, yielding more homogeneous films.

$\mathrm{HfO}_{2}-\mathrm{Y}_{2} \mathrm{O}_{3}{ }^{46}$ is a composite similar to the $\mathrm{ZrO}_{2}-\mathrm{Y}_{2} \mathrm{O}_{3}$ combination just mentioned. This composite film has new properties that the constituent materials do not. Novel and useful properties can be created through the use of composite films. The materials, deposition processes, and reflector designs all can be modified to meet the particular application.

\section{INDUSTRY SURVEY}

A survey was conducted to ascertain the capabilities and limitations of industry as well as to obtain recommendations regarding designs, materials, and processes relevant to the production of UV reflectors for solar application. Existing capabilities and limitations have been mainly dictated by the demand for rnirrors for space and laser applications. The type and size of available mirrors are driven by this market. Most of the reflectors produced are smaller than 24 in. in diameter. Some companies are capable of producing larger reflectors as required by space or defense reflector applications at greatly increased costs. The producible UV reflector designs can be either a dielectric overcoated aluminum or an all-dielectric mirror. However, most high reflectance (>97\%) UV reflectors are all-dielectric mirrors with narrow bandwidths centered on a particular laser wavelength. Deposition of most UV suitable diclectrics can be accommodated, although most companies will not discuss particular designs because of proprietary consideration:. The preferred deposition method appears to be e-beam deposition.

Limitations on the production of UV reflectors for sclar applications are the size and durability of the reflectors. The size limitation manifests itself in the cost of producing large reflectors. The other limitation, durability, is primarily a consequence of the demand for reflectors for use in benign environments such as laboratories. Several vendors felt that they could not satisfactorily protect and maintain reflectance for this particular application. Several other companies did not have expertise in deposicing hard coatings and therefore, could not recommend their products for outdoor use.

Recommendations from companies ranged from considering other substrates, such as stainless steel or metals such as rhodium, to using three to four stacks of dielectrics to obtain broadband high reflectance. Two reflector conct, were generally proposed: dielectric overcoated aluminum first surface mirrors, and all dielectric mirrors. The aluminum overcoated mirrors are the low cost option for a high reflectance broadband mirror. They do, however, have a durability problem because there will always be pinholes in the layers that allow corrosive materials to enter. The all-dielectric mirror was thought to be the more durable of the two. ${ }^{48}$ Such mirrors could reflect only UV wavelengths and transmit visible and near-infrared radiation. Disadvantages include high cost, interlayer stress, and sensitivity to incidence angle.

\section{CONCLUSIONS}

Several new solar technologies aimed at hazardous waste detoxification require UV reflector materials for concentration of sunlight in the spectral range of $300-400 \mathrm{~nm}$. The optical performance requirements are fairly relaxed lecause low levels of concentration are projected. Optical durability, however, is an important issue that needs to bi further aduressed. 
Based upon a review of the literature, a survey of industrial contacts, and available historical weathering data, several UV reflector systems have been identified as candidates for further evaluation. A list of these materials includes

- Bare metals, such as aluminum, rhodium, and platinum

- Protected coatings, particularly thicker anodized aluminum, dielectric overcoats $\left(\mathrm{MgF}_{2}\right.$, oxides, etc.), and polymer (SA85, etc.)

- Enhanced reflectance coatings including multilayer dielectrics and advanced deposition layers (IAD, ion platinis, utc.).

Candidate samples will be subjected to a regimen of outdoor and accelerated exposure tests to provide durability information. Initial (unweathered) optical performance will be characterized. Samples will then be subjected to accelerated and real-time exposure conditions appropriate for their service environment. Optical durability as a function of exposure time will be quantified. This will provide not only a relative ranking of various candidate constructions but may also allow estimates of expected service lifetimes to be made.

\section{ACKNOWLEDGMENTS}

This work was sponsored by the U.S. Department of Energy under contract DE-AC02-83CH10093.

\section{REFERENCES}

1. J.V. Anderson, H. Link, M. Bohn, and B. Gupta, "Development of U.S. Solar Detoxification Technology: An Introduction," presented at the International Energy Agency IEA 5th Syrıposium of Solar High Temperature Technologies, Davos, Switzerland, August 27-31, 1990.

2. C.J. Riordan, R.L. Hulstrom, and D.R.Meyers, "Influences of Atmospheric Conditions and Air Mass on the Ratio of Ultraviolet to Total Solar Radiation," SERI/TP-215-3895, Solar Energy Research Institute, Golden, CO, August 1990.

3. A.B. Meinel, and M.P Meinel, Applied Solar Energy, An Introduction, Addison-Wesley Publishing Company, Reading MA, 246-247, 1977.

4. R.O. Nicolas, and J.C. Duran, "Theoretical Maximum Concentration Factors fur Solar Concentrators," J. Opt. Soc. Am.IA, Vol. 1, no. 11, 1110-1113, November 1984.

5. W.D. Short, "Optical Goals for Polymeric Film Reflectors," SERI/SP-253-3383, Solar Energy Research Institute, Golden, CO, October 1988.

6. P.Bendt, A. Rabl, H.W. Gaul, and K.A. Reed, "Optical Analysis and Optimization of Line Focus Solar Collectors," SERI/TR-34-092, Solar Energy Research Institute, Golden, CO, September 1979.

7. J.D. Rancourt, Optical Thin Films User's Guide, MacMillan Publishing Company, New York, 1987.

8. H. Link, and C. Turchi, "Cost and Performance Projections for Solar Water Detoxification Systems," presented at ASME International Solar Energy Meeting, Reno, NV, March 17-22, 1991.

9. ASTM Standard B 580-79 (Reapproved 1989), "Standard Specifications for Anodic Oxide Coatings on Alumunum," Vol. 2.05, American Society for Testing and Materials, Philadelphia P.A, 337-339, 1990.

10. I. Seddon, "Opportunities in Thin Films to Meet Energy Needs," Business Side of the Optical Industry III, Roderic M. Scott and David A. Treffs, Editors, Proc. SPIE 111, 8-14, 1977.

11. T.A. Facey, "Coatings Yield High UV Reflectance on Spacebon ne Optics," Laser Focus Worla, 107-110, August 1990. 
12. R. Phillips, "Reflector Materials for Ultra-Violet Driers," Transactions of the Institute of Metal Finishing, Vol. 60, 57-62 1982.

13. R.W. Stowe, "Improvements in Efficiency of UV Curing Systems for Optical Fiber Buffer Coatings," Radiation Curing, Conference Proceedings 1986, 3-23 to 3-35, 1986.

14. M. Dunn., J.J. Nemechek, and C.T. Tienvieri, "Making UV Optical Systems Work, A Challenge of Materials and Methods," Lasers \& Optronics, 59-64, April 1989.

15. J.R. Gee, I.J. Hodgkinson, and H.A. Macleod, "Moisture-Dependent Anisotropic Effects in Optical Coatings," Applied Optics, vol. 24, no. 19, 3188-3192, October 1, 1985.

16. D.C. Cranmer, S.W. Freiman, G.S. White, and A.S. Raynes, "Moisture- and Water-Induced Crack Growth in Optical Materials," Optical Surfaces Resistant to Severe Environments, Solomon Musikant, editor, Proc. SPIE 1330, 152-163, 1990.

17. G. Hass, "Filmed Surfaces for Reflecting Optics," J. Opt. Soc. Am., vol. 45, no. 11, 945-952, 1955.

18. G. Hass, "Specular Reflectance of Unprotected and Protected Evaporated Metallic Front-Surface Mirrors at Various Angles of Incidence," J. Vac. Sci. Tech., vol. 16, no. 2, 113-116, 1979.

19. G. Hass, "Reflectance and Preparation of Front-Surface Mirrors for Use at Various Angles of Incidence from the Ultraviolet to the Far Infrared," J. Opt. Soc. Am., vol. 72, no. 1, 27-39, 1982.

20. G. Hass, and A.P. Bradford, "Anodically Produced Multiple Oxide Films for Increasing the Reflectance of Evaporated Aluminum," J. Opt. Soc. Am., vol. 44, no. 10, 810-815, 1954.

21. D.L. Perry, "Low-Loss Multilayer Dielectric Mirrors," Applied Optics, vol. 4, no. 8, 987-991, 1965.

22. A. Roos, and P. Hedenqvist, "Stability Properties of Tin Oxide Aluminum Reflectors," Hard Materials in Optics, Carl G. Ribbing, editor, Proc. SPIE 1275, 148-159, 1990.

23. K.H. Guenther, I. Penney, and R. Wiley, "Corrosion Protection of Front Surface Aluminum Mirror Coatings with Dielectric Thin Films Deposited by Reactive Ion Plating," Thin Films in Optics, Theo Tschudi, editor, Proc. SPIE 1125, 114-121, 1989.

24. D-Y Song, R.W. Sprague, H.A. Macleod, and M.R. Jacobson, "Progress in the Development of a Durable Silver-Based High-Reflectance Coating for Astronomical Telescopes," Applied Optics, vol. 24, no. 8, 1164-1170, April 15, 1985.

25. G.F. Jacobus, R.P. Madden, and L.R. Canfield, "Reflecting Films of Platinum for the Vacuum Ultraviolet," J. Opt. Soc. Am., vol. 53, no. 9, 1084-1088, 1963.

26. D.A. Gulino, R.A. Egger, and W.F. Banholzer, "Oxidation-Resistant Reflective Surfaces for Solar Dynamic Power Generation in Near Earth Orbit," NASA TM-888865, Lewis Research Center, Cleveland OH, Prepared for the 33rd National Symposium of the National Vacuum Society, Baltimore, MD, October 27-31, 1986.

27. W. Gunning, "Gradient-Index Thin Films: An Emerging Optical Coating Technology," Thin Film Technologies III, K.H. Guenther and H.K. Pulker, editors, Proc. SPIE 1019, 204-210, 1988.

28. E.P. Doriovan, D. Van Vechten, A.D.F. Kahn, C.A. Carosella, and G.K. Hubler, "Near Infrared Rugate Filter Fabrication by Ion Beam Assisted Deposition of $\mathrm{Si}_{(1-\times)} \mathrm{N}_{\mathrm{k}}$ Films," Applied Optics, vol. 28, no. 4, 2940-2944, 1989.

29. B.G. Bovard, "Rugate Filter Design: The Modified Fourier Transform Technique," Applied Optics, vol. 29, no. 1, 24-30, 1990. 
30. P.G. Verly, J.A. Dobrowolski, W.J. Wild, and R.L. Burton, "Synthesis of High Rejection Filters with the Fourier Transform Method," Applied Optics, vol. 28, no. 14, 2864-2875, 1989.

31. A.E. Ennos, "Stresses Developed in Optical Film Coatings," Applied Optics, vol. 5, no. 1, 51-61, 1966.

32. L. Belleville, "Processing Developments Support Optical Applications," Laser Focus World, 124-125, 1990.

33. E. Spiller, "Reflective Multilayer Coatings for the Far UV Region," Applied Optics, vol. 15, no. 10, 2333-2338, 1976.

34. F. Spiller, "Low-Loss Reflection Coatings Using Absoioing Materiais," Applied Phys. Lett., vol. 20, no. 9, 365-367, 1972.

35. O.S. Heavens, and H.M. Liddell, "Staggered Broad-Band Reflecting Multilayers," Applied Optics, vol. 5, no. 3, 373-376. March 1966.

36. E. Ritter, "Optical Film Materials and Their Applications," Applied Optics, vol. 15, no. 10, 2318-2327, 1976.

37 P. Gu, and J. Tang, "Excimer Laser Reflectors," Polarization Considerations for Optical System II, R.A. Chipman, editor, Proc.SPIE 1166, 533-541, 1989.

38. H.K. Pulker, "Modern Optical Coatings Techniques," Thin Film Technologies III, K.H. Guenther and H.K. Pulker, editors, Proc. SPIE 1019, 138-147, 1988.

39. P. Baumeister, and O. Arnon, "Use of Hafnium Dioxide in Multilayer Dielectric Reflectors in the Near UV," Applied. Optics, vol. 16, no. 2, 430.444, February, 1977.

40. J.J. McNally, G.A. Al-Ju. .nly, J.R. McNeil, and B. Bendow, "Ion Assisted Deposition of Optical and Protective Coatings for Heavy Metal Fluoride Glass," Applied Optics, vol. 25, no. 12, 1973-1976, 1986.

41. H. Sankur, and R. Hall, "Thin-Film Deposition by Laser-Assisted Evaporation," Applied Optics, vol. 24, no. 20, 3343-3347, October 15, 1985.

42. W. Heitmann, "Properties of Evaporated $\mathrm{SiO}_{2}, \mathrm{SiO}_{x} \mathrm{~N}_{y}$, and $\mathrm{TiO}_{2}$ Films," Applied Optics, vol. 10, no. 12, 2685-2689, 1971.

43. D. Smith, and P. Baumeister, "Refractive Index of Some Oxide and Fluoride Coating Materials," Applied Optics, vol. 18, no. $1,111-115,1979$.

44. F. Rainer, et al., "Materials for Optical Coatings in the Ultraviolet," Applied Optics, vol. 24, no. 4, 496-500, February 15, 1985.

45. D.M. Roessler, and W.C. Walker, "Electronic Spectrum and Ultraviolet Optical Properties of Crystalline MgO," Physical Review, vol. 159, no. 3, 733-738, 1967.

46. J. Tianfgng, $\mathrm{Y}$. Youxin, and $\mathrm{X}$. Juan, " $\mathrm{ZrO}_{2}-\mathrm{Y}_{2} \mathrm{O}_{3}$ and $\mathrm{HfO}_{2}-\mathrm{Y}_{2} \mathrm{O}_{3}$ Composite Coatings for High Power UV Laser Applications," Optical Coatings, T. Jinfa and Y. Yixun, editors, International Academic Publishers, Beijing, 93-97, 1989.

47. F. Stetter, R. Esselborn, N. Harder, M. Friz, and P. Tolles, "New Materials for Optical Thin Films," Applied Optics, vol. 15 , no. $10,2315-2317,1976$.

49. P. Martin, W. Pawlewic\% J. Coult, and J. Jones, "Observation of Exceptional Temperature Humidity Stability in Multilayer Filter Coatings," Applied Optics, vol. 23, no. 9, 1307-1308, May 1, 1984. 


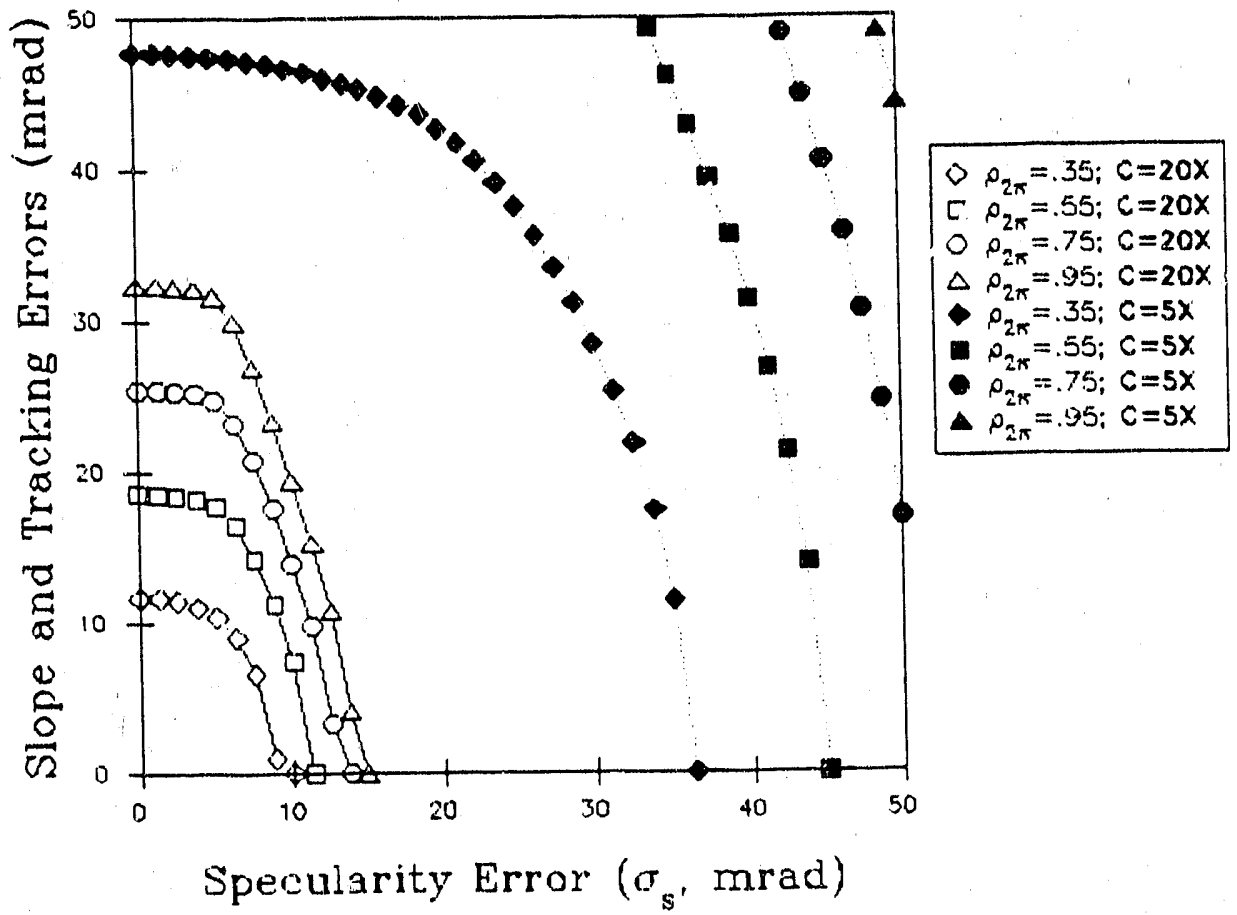

Figure 1. Allowable optical errors to achieve specified concentration levels $(\mathrm{C})$ as a function of hemispherical reflectance $\left(\rho_{2 \pi}\right)$ for trough with $f / D=.35$.

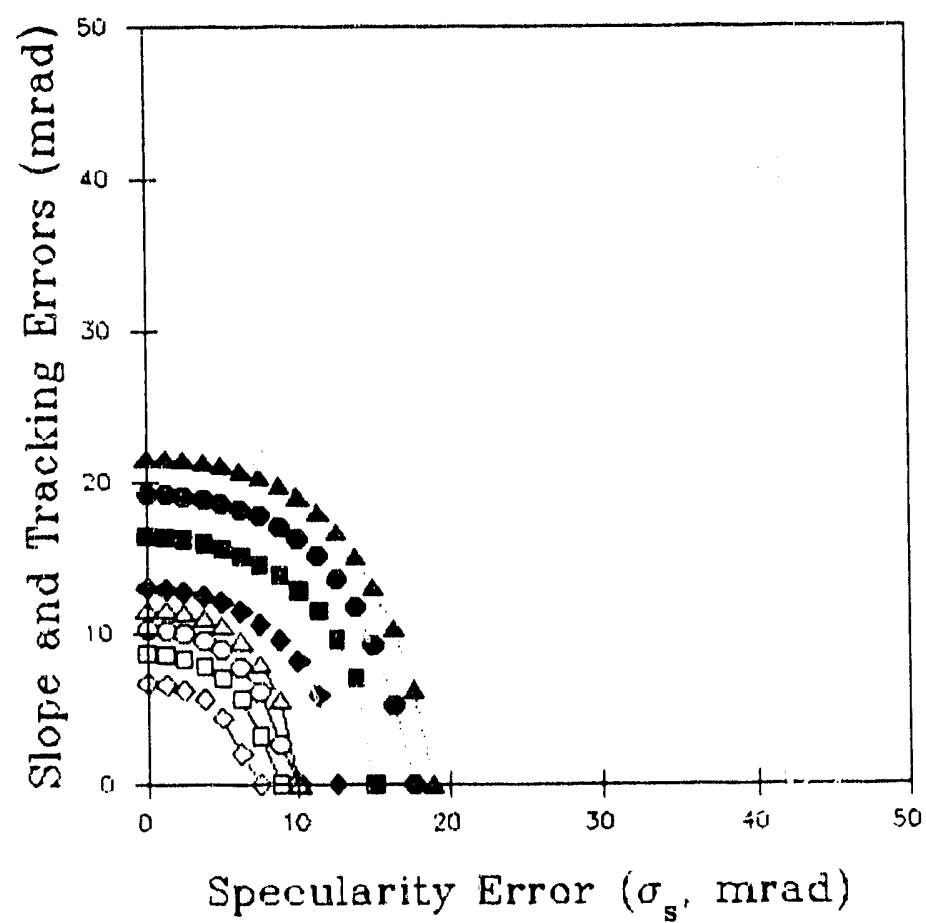

$0 p_{2 \pi}=.35 ; c=1000 x$

ㅁ. $0_{2 \pi}=.55 ; C=1000 x$

$0 p_{2 \pi}=.75 ; c=1000 x$

$\Delta \rho_{2 \pi}=.95 ; c=1000 x$

- $0_{2 \pi}=35: C=300 X$

- $0_{2 \pi}=.55 ; c=300 x$

- $\rho_{2 \pi}=.75 ; c=300 x$

- $\beta_{1 x}=.95 ; c=300 x$

Figure 2. Allowable optical errors to achieve specified concentration levels $(C)$ as a function of hemispherical reflectance $\left(\rho_{2 \pi}\right)$ for dish with $f / D=.6$. 

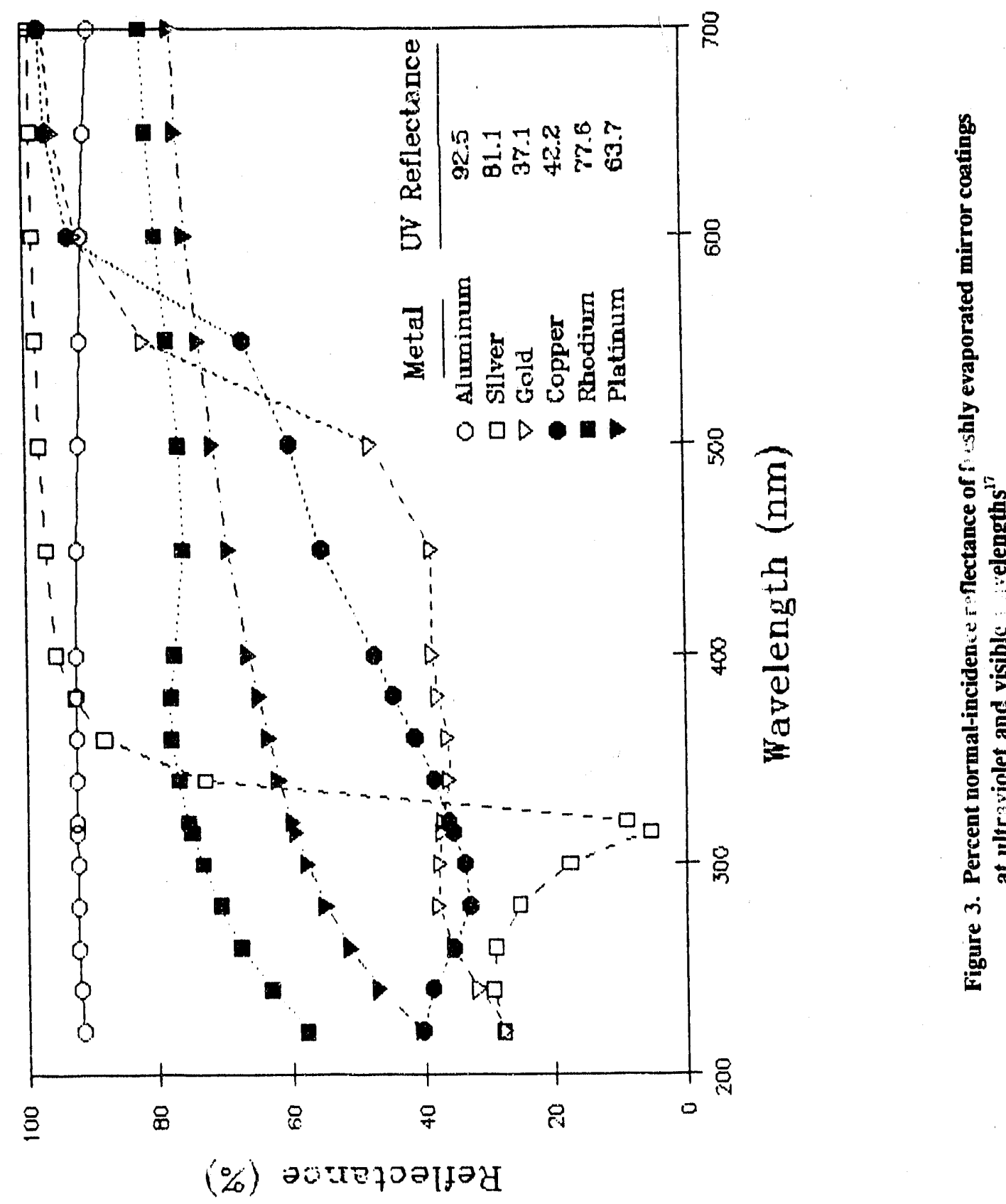

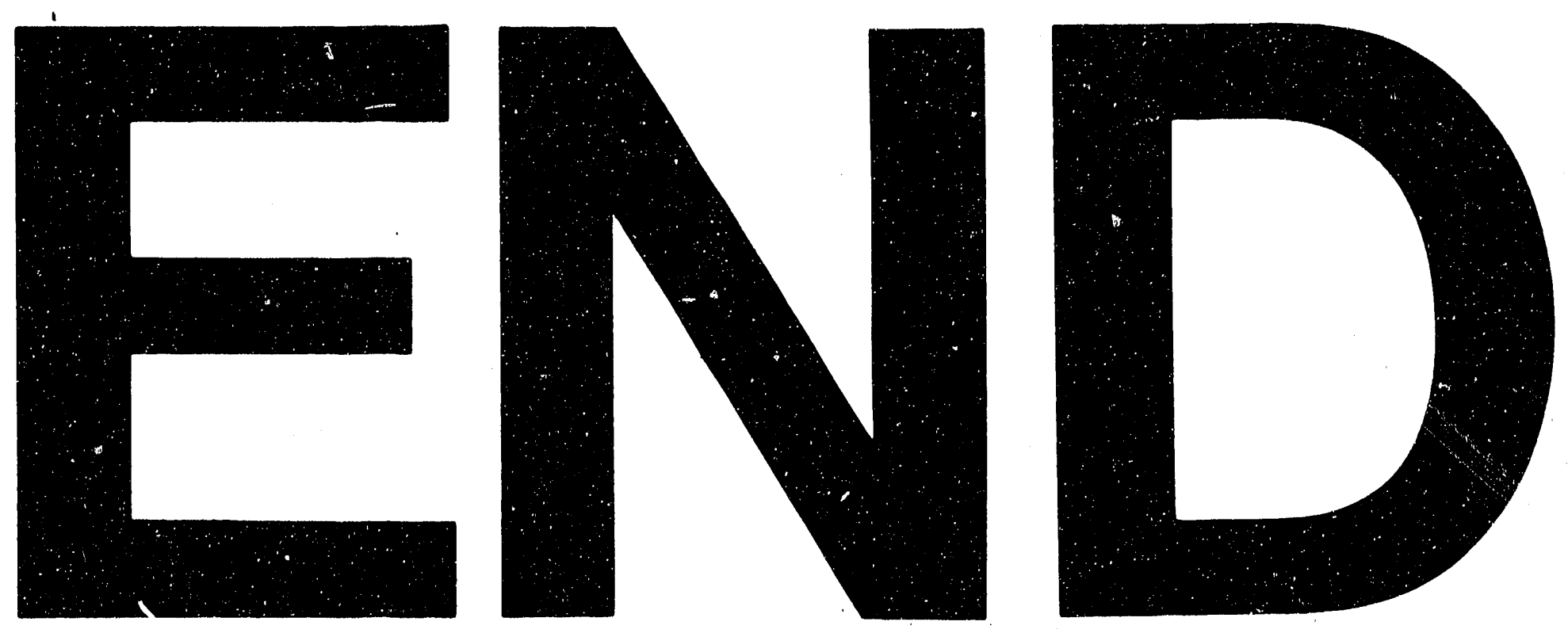

A.2ni $2>2 \times-2$
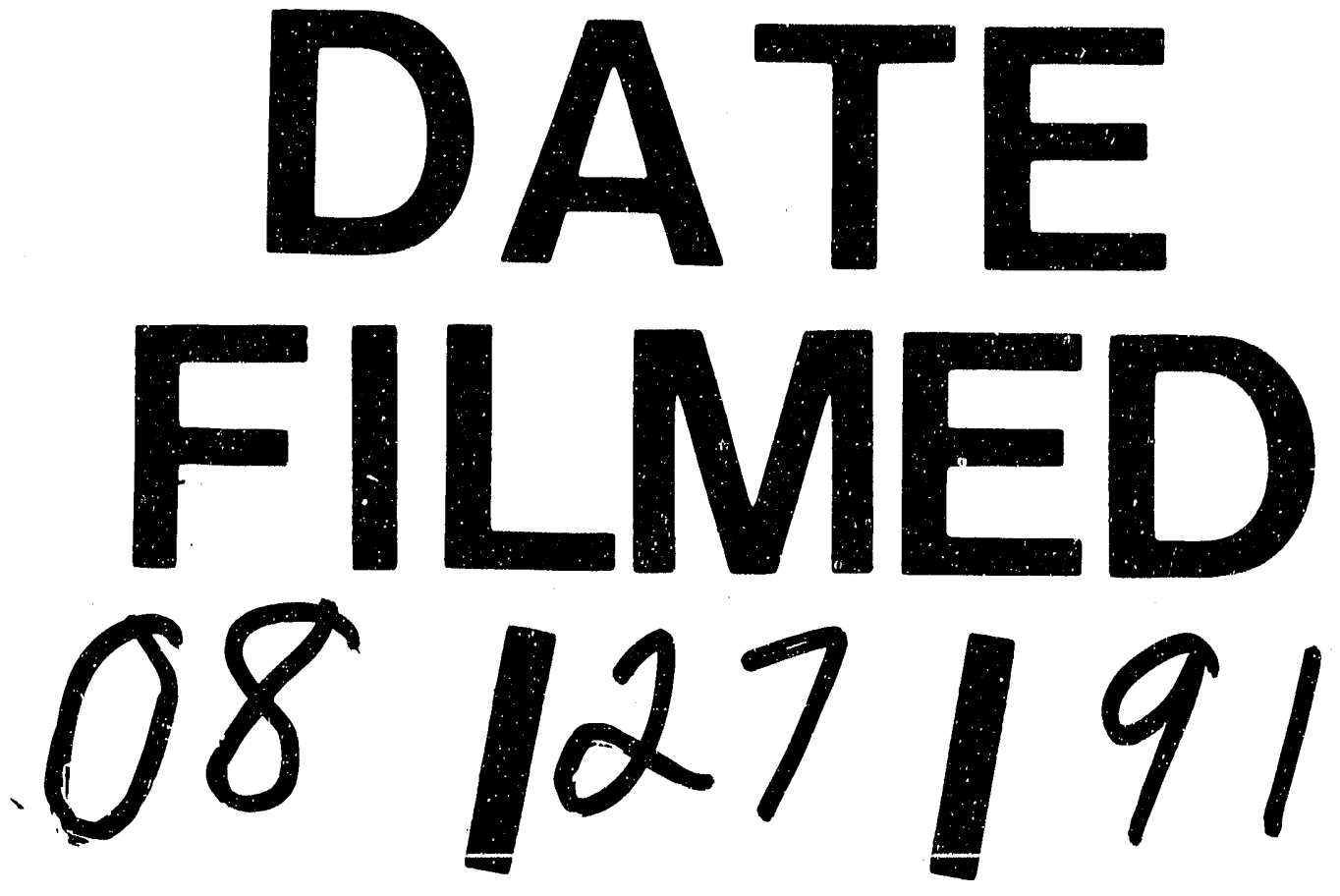
